\title{
ISOLATION AND IDENTIFICATION OF FLAVONOIDS FROM CYPERUS ROTUNDUS LINN. IN VIVO AND IN VITRO
}

\author{
Samariya Krishna* and Sarin Renu \\ Laboratory of bioactive compounds and algal biotechnology, \\ Department of Botany, University of Rajasthan, Jaipur-302004, Rajasthan, India, \\ *Corresponding Author's Email: Krishna_samariya@yahoo.com;renusarin@sify.com
}

\begin{abstract}
Cyperus rotundus (Linn.) is an important medicinal plant belonging to family Cyperaceae. Four Flavonoids such as quercetin, kaempferol, catechin and myricetin were isolated from in vivo (leaf and root) and in vitro callus of this species. These compounds are extensively used in Ayurvedic preparation of medicines and are highly in demand in pharmaceutical industries. The present study therefore was undertaken to determine and compare the production of these flavonoids from in vitro callus culture and in vivo plant parts of $C$. rotundus. Quantification data revealed that the total flavonoid content (free + bound) was higher in tissue culture than in plant parts. The maximum amount of total flavonoid was found in six weeks old callus tissue (1.96mg/g.d.w) and minimum $(0.28 \mathrm{mg} /$ g.d.w) in two week old callus tissue. In vivo studies showed higher flavonoids content in leaf in free form $(0.58 \mathrm{mg} /$ g.d.w. $)$ and bound form $(0.48 \mathrm{mg} /$ g.d.w. $)$ when compared to root in free form $(0.19 \mathrm{mg} / \mathrm{g} . \mathrm{d} . \mathrm{w})$ and bound form $(0.11 \mathrm{mg} / \mathrm{g} . \mathrm{d} . \mathrm{w})$.
\end{abstract}

Keywords: Cyperus rotundus, Callus culture, Flavonoids

\section{INTRODUCTION}

Medicinal plants are rich source of secondary metabolites, exerting specific physiological effect on mammalian system and hence called active principles. Secondary metabolites include various compounds biosynthetically derived from primary metabolites but restricted to specific taxonomic genera of plant kingdom and specific part of plant body.

Flavonoids, one of the important groups of secondary metabolites, are water soluble phenolic glycosides imparting colour to flowers and fruits of higher plants. Their contribution to physiological functions such as seed maturation and dormancy has already been established. ${ }^{1} \mathrm{~A}$ simple definition describes flavonoids as "any group of substances found in fruits and vegetables essential for processing vitamin- $\mathrm{C}$ and needed to maintain capillary wall". They may aid in protecting against infection. Deficiency can result in bruise. In chemical structure, flavonoids are polyphenolic compounds possessing 15 carbon atoms, two benzene rings joined by a linear 3 carbon chain. They are usually subdivided according to their substituents into flavanols (kaempferol, quercetin), anthocyanins, flavones, flavonones and chalcones. These flavonoids display a remarkable array of biochemical and pharmacological actions viz., antiinflammatory, antioxidant, antiallergic, hepatoprotective, antithrombotic, antiviral and anticarcinogenic activities ${ }^{2}$. These compounds appear to play vital roles in defence against pathogens and predators and contribute to physiological functions such as seed maturation and dormancy ${ }^{3}$. They are synthesized from phenyl propanoid and acetate derived precursors. Quercetin works as antiinflammatory, antioxidant, anticancer agents ${ }^{4}$. Quercetin functions like other flavonoids in enhancing the collagen network (structural integrity) of blood vessel. It also helps in solving problems of cellular regeneration hemorrhoids, menopausal symptoms and non healing ulcers. Three flavonols(quercetin,myricetin, and of tested plants is attributed to polyphenolic antioxidant components. Flavonoids are widely distributed polyphenolic compounds and acts as free radical scavengers by fast donation of hydrogen atoms to free radicals. Antioxidant activity of flavonoids is largely depend on the molecular structural (availability of phenolic hydrogen atom) and substitution pattern of hydroxyl groups, which effects on the stability of resulting phenoxyl radical by hydrogen bond or delocalization of free electron 5 .

\section{MATERIAL AND METHODS}

Plant parts of Cyperus rotundus L. (Cyperaceae) were collected from Nursery, University of Rajasthan (Jaipur). For in vitro studies leaves and roots were used as explants. Tuber explants of $0.5-1.0 \mathrm{~cm}$. long were used for regeneration. The explants were washed with running tap water pre soaked in $0.1 \%$ liquid detergent for about 30 min. Subsequently explants were surface sterilized with $70 \%$ ethyl alcohol for 30 seconds followed by $0.1 \%(w / v)$ $\mathrm{HgCl}_{2}$ containing $0.2 \mathrm{ml}$ Tween 80 per $100 \mathrm{ml}$ of solution for 1 minute. The explants were rinsed several times with sterile double distilled water.

The excised explants were then inoculated in culture flasks containing 30-35 ml MS medium (Murashige and Skoog $1962)^{6}$ supplemented with 3\% (w/v) sucrose, $0.8 \%(w / v)$ agar (Qualigens, India), and B5 (Gamborg et al. 1968) ${ }^{7}$ vitamins. Auxins (Indole 3- acetic acid, 2,4Dichlorophenoxy acetic acid, and Napthalene acetic acid,), cytokinin (6- benzylaminopurine, kinetin) were incorporated into basal medium in varying concentrations and combinations as indicated in the results. The $\mathrm{pH}$ of all the media combinations was adjusted to $5.8 \pm 0.1$ using $0.1 \mathrm{~N} \mathrm{NaOH}$ or $0.1 \mathrm{~N} \mathrm{HCl}$ before autoclaving. Autoclaving was done at $1.06 \mathrm{~kg} \mathrm{~cm}-2$ at $121^{\circ} \mathrm{C}$ for 25 minutes. Cultures were incubated at $24^{\circ} \pm 2^{\circ} \mathrm{C}$ temperature and 55 
$\pm 5 \%$ relative humidity with 16 hours photoperiod. All treatments had 4 to 8 replicates. Each culture flask contained $30 \mathrm{ml}$ of culture medium and 4 explants were inoculated per flask. All experiments were repeated thrice. The calluses were subcultured on fresh media every two weeks depending on the rate of callus growth. Explants showing no visible callus growth or with slow growing callus were transferred to fresh media every four weeks. The growth index was calculated after every two weeks time interval. Callus was initiated from tuber explants on MS medium supplemented with 2,4-D (2.0 mg/l) and Kinetin $(0.5 \mathrm{mg} / \mathrm{l})$ after $28-30$ days..Culture was maintained at $26+1 \mathrm{c}, 55 \%$ humidity with $18 \mathrm{hrs}$. and light intensity (300 lux) and then analyzed for their flavonoids content and compared with that of contents present in plant parts. Presence of flavonoids in various tissue samples and plant parts of $C$. rotundus were confirmed by TLC and IR spectral studies.

\section{Flavonoids}

Extraction procedureDifferent plant parts as well as tissue samples $(2,4,6$ and 8 weeks old) of $C$. rotundus were air dried, powdered and used for extraction of flavonoids. Each of the dried powdered and weighed sample was soxhlet extracted in $80 \%$ methanol for $24 \mathrm{hrs}^{8}$ and filtered. The methanol soluble fractions were filtered, concentrated in vacuo and the aqueous fractions fractioned by sequential extraction with petroleum ether $\left(40-60^{\circ}\right.$; fraction I), ethyl ether (fraction II) and ethyl acetate (fraction III) in succession. Each step was repeated thrice to ensure complete extraction. Fraction I was rejected due to its being rich in fatty substances, whereas fraction II was analysed for free flavonoids and fraction III for bound flavonoids. Fraction III of each of the samples was separately hydrolyzed with $7 \% \mathrm{H}_{2} \mathrm{SO}_{4}$ (10 $\mathrm{ml} / \mathrm{gm}$ residue) for $2 \mathrm{hr}$. The mixture was filtered and the filtrate extracted with ethyl acetate in a separating funnel. Some amount of water was also added to separate the two layers. The ethyl acetate layer (upper) was washed with distilled water to neutrality, dried in vacuo and analyzed for bound flavonoids.

\section{Chromatographic analysis}

\section{(I) Thin layer chromatography (TLC)}

A. QualitativeThe glass plates $(20 \times 20 \mathrm{~cm})$ thinly coated with silica gel $\mathrm{G}(250 \mathrm{~m} \mu$ thick $)$ and activated at $100^{\circ}$ $\mathrm{C}$ for $30 \mathrm{~min}$ and cooled. Ethyl ether and ethyl acetate fractions were separately applied $1 \mathrm{~cm}$. above the edge of the plates along with the standard reference compounds (Quercetin, Kaempferol, Catechin, Myricetin), the chromatograms were developed in a saturated air tight chromatographic chamber containing about $200 \mathrm{ml}$. with solvent mixture (Butanol : acetic acid: water, 125:72:3) Wong and Francis, 1968. A few other solvent systems (n-butanol and water $1: 1$, ethyl acetate, acetic acid and water 4 : $1: 5$, benzene and ethyl acetate $85: 15$ ) were also tried, but in the present study the organic solvent mixture of butanol, acetic acid and water gave excellent results. The developed plates were air dried and visualized under UV light alone and in the presence of ammonia fumes (kept in a chamber containing concentrated ammonium hydroxide for about 10-15 sec.). The fluorescent spot coinciding to authentic quercetin was identified (free and bound) as quercetin (blue). The color of spots changed to bright yellow when exposed to ammonia fumes. In each sample Rf values for quercetin were calculated ( $\mathrm{Rf}$ 0.78 ) as an average of five replicates and compared with those of standards. A few plates were also sprayed with $5 \% \mathrm{FeCl} 3$. The identification of isolated flavonoids (Quercetin, Kaempferol, Catechin, and Myricetin) was done by $\mathrm{mp}, \mathrm{mmp}$, performed in capillaries (Toshniwal Melting Point Apparatus), IR (Infra -red spectrophotometer; Perkin, Elmer 337, Grating Infra - red spectrophotometer) UV (Ultraviolet and visible spectrophotometer ; Carl Zeiss, Jena, DDR, VSU-ZP spectrophotometer) analysis along with their respective authentic samples.

\section{(II) Preparative thin layer chromatography (PTLC)}

Glass plates $(20 \times 20 \mathrm{~cm})$ thickly coated $(0.4-0.5 \mathrm{~nm})$ with silica gel ' $\mathrm{G}$ ' (45 gm/80 $\mathrm{ml}$ water) dried at room temperature, activated at $100^{\circ} \mathrm{C}$ for 30 minutes and cooled at room temperature were used for preparative thin layer chromatography (PTLC). The various extracts along with the standard samples of kaempferol, quercetin, catechin and myricetin were applied $1 \mathrm{~cm}$ above the edge of the glass plate. These glass plates developed in an air tight chromatographic chamber containing about $200 \mathrm{ml}$ of organic solvent mixture of n-butanol,acetic acid and water (4:1:5 upper layer). The developed glass plates were dried at room temperature.

The developed plates were dried and visualized under UV light. Florescent spots coinciding with those of the standard reference compounds of kaempherol and quercetin were marked. The marked spots were scrapped and collected separately along with the adsorbent and eluted with ethyl acetate. Each of the elutes was obtained out of both diehyl ether and ethyl acetate extracts were dried over sodium sulphate, reconstituted in chloroform and crystallized. The same process was followed alike for both the ethyl ether and ethyl acetate fractions from each of the extracts.

The substances thus isolated were purified, crystalised, weighed and percentage calculated separately on dry weight basis. Each of the substances was then subjected to $\mathrm{mp}$, Ultra violet and IR spectral studies using nuzol or $\mathrm{kBr}$ pallets $9,10,11$. This purified material was also subjected to HPLC studies (Water associates, column - microporasil, $80 \%$ hexane and $20 \%$ ethyl acetate, chart spectra 1 $\mathrm{cm} / \mathrm{min}, 0.5 \mathrm{ml} / \mathrm{min} \mathrm{UV} \mathrm{detector} \mathrm{at} 254 \mathrm{~nm}$ ).

\section{B. Quantification}

The identified kaempferol (K), querecetin (Q) and myristin (M) were quantitatively estimated by spetrophotometric methods of Mabry et al., (1970)12 and Kariyone et al., (1953)13 respectively, which included the computation, of their regression curves.

Stock solutions of $\mathrm{K}, \mathrm{Q}$ and $\mathrm{M}$ were prepared in methanol $(1 \mathrm{mg} / \mathrm{ml})$, out of which varied concentrations $(20 \mu \mathrm{g}$ to $160 \mu \mathrm{g})$ were separately spotted on TLC plates, developed above, air-dried and visualized under UV light as also I2 vapors. The spots marked on the basis or fluorescence were collected along the absorbent in separate test tubes. Later, to each $5 \mathrm{ml}$ of spectroscopic methanol was added 
shaken vigorously, centrifuged and the supernatants were collected separately. The volume of each was raised to 10 $\mathrm{ml}$ by methanol, to which $3 \mathrm{ml}$ of $0.1 \mathrm{M} \mathrm{AlCl} 3$ solution was added by vigorous shaking and kept at room temperature for $20 \mathrm{~min}$. The OD of each of the sample was taken on a spectrophotometer set at $424 \mathrm{~nm}$ for K, $440 \mathrm{~nm}$ for $\mathrm{Q}$ and $424 \mathrm{~nm}$ for $\mathrm{M}$ against, the blank and the average of five replicates of each was calculated. A regression curve for each of those authentic compounds (K, Q and M) was plotted in between the various concentrations and their respective ODs, which followed the Beer's Law.

\section{RESULTS}

Callus of C. rotundus L. was initiated from young rhizomes and tubers on MS basal medium supplemented with different concentrations of phytohormones. The concentrations of different phytohormones taken of 2,4-D, $\mathrm{NAA}$ and $\mathrm{KN}$ either in isolation or combination with each other. Callus so formed was pale white, soft, and slow growing. The callus was obtained within two weeks. The best growth of callus was seen in 2,4-dichloro phenoxyacetic acid (2,4-D) $2.5 \mathrm{mg} /$ litre and Kinetin $0.5 \mathrm{mg} /$ litre.

\section{DISCUSSION}

Quantification data revealed that the total flavonoid content (free+bound) was more in leaf when compared to root. The total flavonoids in their bound form were highest in leaf and lowest in roots. The total free and bound kaempherol content was highest in leaf and lowest in roots. The total quercetin content was highest in leaf and lowest in root. The in vitro studies showed that the maximum amount of total flavonoid content was in 6-week old tissue and minimum was in 2-week -old tissue. The total amount of kaempherol was maximum in 6-week old tissue and minimum in 2-week -old tissue. However, the total amount of quercetin was highest in 8 weeks old tissue and lowest in 4 week old tissue. (Table1-4)

Quercetin (Rf-0.78; UV - fluorescent yellow; Ammonia deep yellow; $\mathrm{FeCl} 3$ - Bluish grey; $\mathrm{mp}-309-310^{\circ} \mathrm{C}$ ). The characteristic IR spectral peaks were found to be superimposable with those of their respective standard reference compound of quercetin. C.rotundus roots has highest amount of quercetin. Myricetin and kaempferol are also present in good quantities. It contains gallic acid, P-coumaric acid, ferulic acid and chlorogenic acids. C. rotundus rhizomes have good combination of phenolic acids and flavonols, which contributes collectively to the strong antioxidant action of rhizomes.

\section{ACKNOWLEGEMENT}

The authors would like to acknowledge with thanks to CSIR, New Delhi for granting SRF to one of the authors (Krishna Samariya) and Head, Department of Botany, University of Rajasthan, Jaipur for providing all the facilities in the Department to carry out the research work.

Table 1: Total flavonoid content (free+bound) $(\mathrm{mg} / \mathrm{gdw})$ in different plant parts of $C$. rotundus

\begin{tabular}{|c|c|c|c|c|c|c|c|c|c|}
\hline \multirow[t]{2}{*}{$\begin{array}{c}\text { S. } \\
\text { No. }\end{array}$} & \multirow[t]{2}{*}{$\begin{array}{l}\text { Plant } \\
\text { parts }\end{array}$} & \multicolumn{3}{|c|}{$\begin{array}{l}\text { Free flavonoids } \\
\quad(\mathrm{mg} / \mathrm{gdw})\end{array}$} & \multicolumn{2}{|c|}{$\begin{array}{c}\text { Bound flavonoids } \\
(\mathrm{mg} / \mathrm{gdw})\end{array}$} & \multirow[t]{2}{*}{$\begin{array}{c}\text { Total Kaempferol } \\
(\mathrm{mg} / \mathrm{gdw})\end{array}$} & \multirow[t]{2}{*}{$\begin{array}{l}\text { Total Quercetin } \\
(\mathrm{mg} / \mathrm{gdw})\end{array}$} & \multirow{2}{*}{$\begin{array}{c}\text { Total Flavonoids } \\
\text { (free+bound) } \\
(\mathrm{mg} / \mathrm{gdw})\end{array}$} \\
\hline & & $\mathrm{K}$ & $\mathrm{Q}$ & total & $\mathrm{Q}$ & total & & & \\
\hline 1. & Root & 0.10 & 0.09 & 0.19 & $0.04 \quad 0.07$ & 0.11 & 0.14 & 0.16 & 0.30 \\
\hline 2. & Leaf & 0.15 & 0.43 & 0.58 & $\begin{array}{ll}0.13 & 0.35\end{array}$ & 0.48 & 0.28 & 0.78 & 1.06 \\
\hline
\end{tabular}

Table 2: Growth indices and total flavonoid content in vitro (free+bound)(mg/gdw) in different plant parts of $C$. rotundus

\begin{tabular}{|c|c|c|c|c|c|c|c|c|c|c|}
\hline \multirow[t]{2}{*}{$\begin{array}{l}\text { S. } \\
\text { No. }\end{array}$} & \multirow{2}{*}{$\begin{array}{l}\text { Age of } \\
\text { Tissue } \\
\text { In weeks }\end{array}$} & \multirow[t]{2}{*}{$\begin{array}{l}\text { Growth } \\
\text { Indices }\end{array}$} & \multicolumn{3}{|c|}{$\begin{array}{l}\text { Free flavonoids } \\
(\mathrm{mg} / \mathrm{gdw})\end{array}$} & \multicolumn{2}{|c|}{$\begin{array}{l}\text { Bound flavonoids } \\
(\mathrm{mg} / \mathrm{gdw})\end{array}$} & \multirow{2}{*}{$\begin{array}{l}\text { Total } \\
\text { Kaemp } \\
\text { ferol } \\
(\mathrm{mg} / \mathrm{gd} \\
\mathrm{w})\end{array}$} & \multirow{2}{*}{$\begin{array}{l}\text { Total } \\
\text { Quercetin } \\
(\mathrm{mg} / \mathrm{gdw})\end{array}$} & \multirow{2}{*}{$\begin{array}{l}\text { Total } \\
\text { Flavonoids } \\
\text { (free+bound) } \\
\text { (mg/gdw) }\end{array}$} \\
\hline & & & & $\bar{Q}$ & total & $\begin{array}{l}\mathrm{K} \\
\text { total }\end{array}$ & Q total & & & \\
\hline 1. & 2 & 0.18 & 0.08 & 0.06 & 0.12 & 0.05 & $0.09 \quad 0.14$ & 0.13 & 0.15 & 0.28 \\
\hline 2. & 4 & 0.45 & 0.25 & 0.47 & 0.72 & 0.26 & $0.42 \quad 0.68$ & 0.51 & 0.89 & 1.40 \\
\hline 3. & 6 & 1.36 & 0.43 & 0.73 & 1.16 & 0.32 & $0.48 \quad 0.80$ & 0.75 & 1.21 & 1.96 \\
\hline 4 & 8 & 0.67 & 0.33 & 0.54 & 0.87 & 0.24 & $\begin{array}{ll}0.33 & 0.57\end{array}$ & 0.57 & 0.87 & 1.44 \\
\hline
\end{tabular}


Table 3: Chromatographic data and colour reaction of the flavonoids isolated from different plant parts of $C$. rotundus

\begin{tabular}{|l|c|c|c|c|c|c|c|}
\hline Flavonoids & \multicolumn{3}{|c|}{$\mathrm{Rf}(\times 100)$ in BeAW } & \multicolumn{2}{c|}{ Colour reaction } & mp $^{\circ} \mathrm{C}$ & $\begin{array}{c}\text { UV } \\
\text { maximum }\end{array}$ \\
\hline & Standard & Leaf & Root & Day- light & $\mathrm{I}_{2}$ vapours & & \\
\hline Kaempferol & 85 & 83 & 78 & GN-YW & YW-BN & $271-273$ & 268,368 \\
\hline Quercetin & 78 & 75 & 73 & GN-YW & YW-BN & $309-311$ & 258,373 \\
\hline Myricetin & 50 & - & 49 & GN-YW & YW & $332-335$ & 248,358 \\
\hline Catechin & 0.19 & 0.15 & - & BT-YW & YW & $328-330$ & 252,354 \\
\hline
\end{tabular}

Abbreviations: ${ }^{+}$BeAW $=$Benzene $:$Acetic acid $:$Water $(125: 72: 3) ; B K=$ Black; $B N=$ Brown; $B T=$ bright DL $=$ dull; GN $=$ green; $Y W=y e l l o w$

Table 4: Isolated flavonoid content $\left(\mathrm{mg} / \mathrm{gdw}^{*}\right)$

\begin{tabular}{|l|c|c|c|c|c|}
\hline C. rotundus & Kaempferol & Quercetin & unknown & Myricetin & Catechin \\
\hline Root & - & 0.09 & 0.04 & 0.10 & - \\
\hline Leaves & 0.15 & 0.43 & - & - & 0.43 \\
\hline
\end{tabular}
L $\quad$ R $\quad$ C $\quad$ S

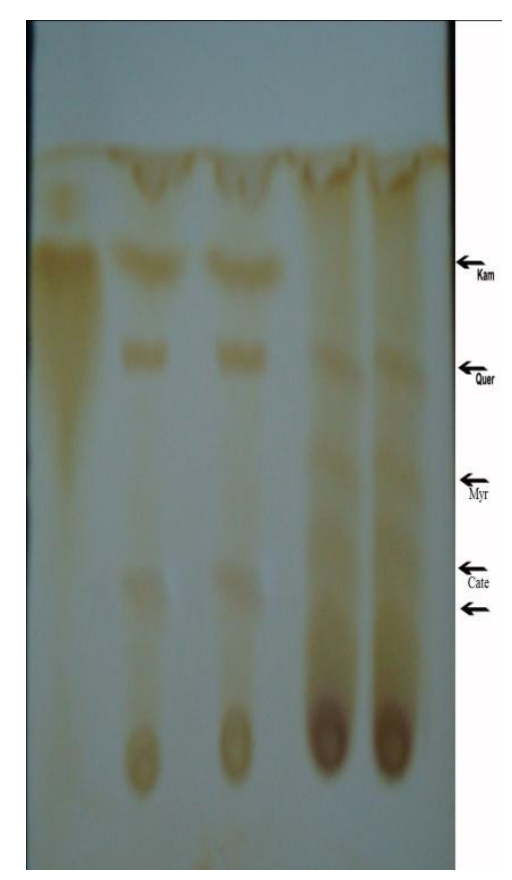

Figure 1: TLC plates showing presence of kaempherol,quercitin, myristein and catechol respectively of isolated in vivo and in vitro samples of $C$. rotundus (In vivo $\mathrm{L}=$ leaf, $\mathrm{R}=$ root, $\mathrm{C}=$ in vitro callus)

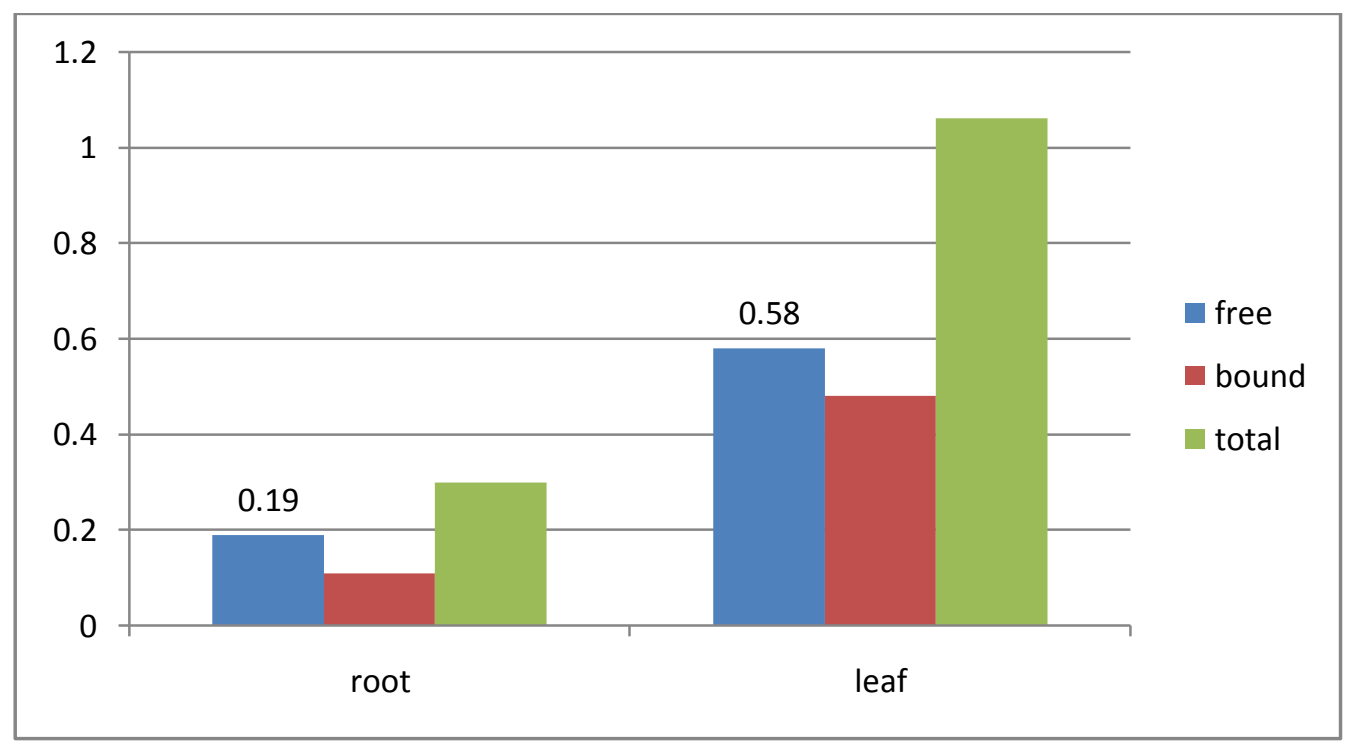

Figure 2: Total flavonoid content (free+bound) $(\mathrm{mg} / \mathrm{gdw})$ in different plant parts of $C$. rotundus 


\section{REFERENCE}

1. Brenda W S 1998 Flavonoids in seeds and grains: Physiological function, agronomic importance and the genetics of biosynthesis. Seed Sci Res 8 415-422.

2. Middleton E and Kandaswami C (1993) : The impact of plant flavonoids on mammalian biology: Implications for immunity, inflammation and cancer, in the flavonoids, Advances in Research Science (Ed.) Harborne, I R , Chapman and Hall, London, pp; 619-645.

3. Winkel-Shirley, B. (2002) : Biosynthesis of flavonoids and effects of stress. Curr. Opin. Plant Biol., 5, 218-223

4. Lamson D.W. and Brignale M S (2000) : Antioxidants and cancer III : quercetin. Alt. Med. Rev., 5, 196-208.

5. Amic, D., D. Davidovic-Amic, D. Beslo and N. Trinajstic, 2003. Structure-radical scavenging activity relationship of flavonoids. Croatia Chem. Acta, 76: 55-61.

6. Murashige, $\mathrm{T}$ and Skoog, $\mathrm{F}$ A revised medium for rapid growth and bioassays with tobacco tissue cultures. Physiol. Plant. 1962; 15:473-497.

7. Gamborg O L, Miller R A and Ojima K 1968.Nutrient requirements of suspension cultures of soyabean root cells.Exp cell Res 50 151-158.
8. Subramanian S S and Nagarajan S. (1969) : Flavonoids of the seeds of Crotlaria retusa and C.striata. Curr. Sci., 38, 6568.

9. Casteel, H W and S M Wender. Identification of flavonoid compounds, Rf values and colour tests.Anal.Chem.,25: 55-62. (1953).

10. Harborne, J.B.," Phytochemical methods", Chapman and Hall,London. (1973).

11. Sayagaver,B M,N B Mulchandani and S. Narayanswamy. Isolation of formononetin from tissue cultures of Cicer arietinum Lloydia 32: 108-109. (1969).

12. Mabry T J, Markham K R, Thomas M B. The Systematic Identification of Flavonoids. New York: Springer-Verlag Publication; 1970. pp. 261-266.pp. 294

13. Kariyone T, Hashimoto Y \& Kimura M (1953).Microbial studies of plant components. IX. Distribution of flavonoids in plants by paper chromatography.J. Pharma Soc (Japan) 73253 256. 